\title{
Association between quality of family planning services and client's satisfaction level in maternal and child health centers in Port Said city
}

\author{
Elsayda Hamdy Nasr ${ }^{1}$, Hanan Elzeblawy Hassan *2 \\ ${ }^{1}$ Faculty of Nursing, Port said University, Port said, Egypt \\ ${ }^{2}$ Faculty of Nursing, Beni-Suef University, Beni-Suef, Egypt
}

\author{
Received: September 22, 2015 \\ Accepted: October 8, 2015 \\ Online Published: October 19, 2015 \\ DOI: $10.5430 /$ jnep.v6n1p85 \\ URL: http://dx.doi.org/10.5430/jnep.v6n1p85
}

\begin{abstract}
Background: Improving quality of care has been a necessary goal for family planning programmes worldwide. Services should be convenient, accessible and acceptable to clients. In addition, it is essential to provide follow-up care to ensure continuity of services and an adequate logistics system to ensure continuity of supplies. Patient satisfaction is reportedly a useful measure to provide a direct indicator of quality in health care. Thus, it is needed to be measured frequently. Aim: To assess the association between quality of family planning services and client's satisfaction level in maternal \& child health centers in Port Said city.

Subject and Methods: A cross sectional descriptive research design included two main convenient samples were recruited in the study through 5 months, the family planning nurses (20) and clients attending these centers (240). The study was carried out at ten family planning clinics in ten centers representing the five districts of Port Said.

Results: Statistically significant difference correlation was found between quality of family planning counseling of nurses practice and their number of received training program, the mean percentage of the client's $(95.4 \%)$ were satisfied with family planning services.

Conclusions: The number of received training program affects quality of family planning counseling of nurse's practice, providers of the services and the provided services affect the client satisfaction.
\end{abstract}

Key Words: Quality, Family planning, Services, Client's satisfactions

\section{INTRODUCTION}

The assessment of quality of service has posed as a challenge for improving the efficiency and effectiveness of primary health care. where basic health services including maternal and child health services are provided at commune health centers. $^{[1]}$ A concrete and useful way to create an action plan for improving the quality of maternity care is to start with a view of the desired result, a common definition and a shared vision for a high-quality, high-value maternity care system. ${ }^{[2]}$ Improving quality of family planning services offers many benefits; information and service will be accessible, clients make informed decisions, and public will have a more positive view of health care and its providers. In last decades Egypt had suffered major socioeconomic consequences of overpopulation problem. This resulted from high level of birth rate. ${ }^{[3]}$ Every 10 seconds the world population Egypt.

*Correspondence: Hanan Elzeblawy Hassan; Email: nona_nano_1712@yahoo.com; Address: Faculty of Nursing, Beni-Suef University, Beni-Suef, 
increases by 30 individuals and is likely doubled over the next 40 years. Over population and unplanned population growth impede the socioeconomic development, hinder prosperity, and threatens the health status of community members. ${ }^{[4]}$

Therefore, family planning is achieved through contraception which is defined as any means capable of preventing pregnancy. ${ }^{[5]}$ Family planning is today considered as important in reproductive health and human rights. It is an important component of primary health care, maternal and child health. It is the means of planning families that are want space according to choice and time to fit in with life decisions. Contraception is an important issue for all couples, and the method used should be decided by the women and her partner jointly. This process is facilitated by establishing a trusting relationship with the client and by providing unbiased, accurate information about all methods available. ${ }^{[6]}$ Adequate communication enhances family planning acceptance, client satisfaction, as well as effective and continued use of contraception. ${ }^{[7]}$

There are many factors, which affect women utilization of family planning services. These factors mentioned as by Veres et al. (2004); Factors related to contraceptive methods as (safety of the method, effectiveness, availability and the cost of all contraceptive methods); Factors related to the couples using contraceptives includes (demographic and biological factors as age of women, maternal education and husband education, parity, Sociocultural factors, occupational and economic factors, religious factors, legal factors and psychological factors). ${ }^{[8]}$

Good quality means "doing the right things right". ${ }^{[9]}$ Quality in health care and family planning has been defined in many ways. ${ }^{[10]}$ From public health perspective, quality means offering the general health benefits, with the list health risk to the greater number of people, given the available resources. Also, good quality means either meeting minimal standards for adequate care or achieving high standards of excellence. Quality can refer to the technical quality of care to the nontechnical aspect of service delivery such as clients' waiting time and staff attitudes, and to programmatic elements such as policies, infrastructures, access, and management. ${ }^{[1-13]}$ In health care and Family Planning Program service, this means offering a range of services that is safe, effective and that satisfy clients' needs and wants.

However, most evaluation studies deal with quality either according to the "technocratic" perspective of health care professionals or from the lay perspective of clients or communities. In the former perspective, services are judged to be good quality if they reach standards defined by health professionals. ${ }^{[14]}$ The international Planned Parenthoods Federation (IPPF) has played a great role in the expansion of family planning program worldwide. International Planned Parenthoods Federation has adopted the concept of sexual and reproductive health agenda in its vision 2000. In 1994, the International Conference on Population and Development (ICPD) held in Cairo gave great attention to IPPF's reproductive and sexual health agenda. It emphasized peoples' right to reproductive health and the most important was quality service. Service should be accessible, acceptable, and convenient to all contraceptive users. ${ }^{[15]}$ In addition to the role of clients' right, choice and consent had been strongly indorsed by most nations of the world through support of the program of action of the 1994 ICPD in Cairo. These rights rest on the recognition of the basic rights of all couples and individuals to decide freely and responsibly the number, spacing, timing of their children and to have information and means to do so. ${ }^{[16]}$ The decision has to be made freely without any coercion, after the individual has been fully informed about the benefit of planning of family size, the methods one can use, the relative advantage and disadvantage of the method as well as the expected side effects of all the methods they are provided.

In the latter, clients play a central role in defining and assessing quality of health care. There has been some debate about using the client's perspective in evaluation of the quality of services. While many stakeholders have viewed the client's perspective as a meaningful indicator of health services quality, others have dismissed the views of clients as too subjective. For the latter point of view, how a client feels is important, even though the provider's assessment of reality may be different, because at a minimum, the subjective assessment of quality by clients can still provide useful input to help the provider understand and establish acceptable standards of services. ${ }^{[17]}$ As it is very difficult to assess a full range of evaluations, particularly negative ones, the client's perspective has been seen as an undetectable part of health care evaluations. ${ }^{[18]}$

\subsection{Significance of the study}

Quality has different meaning to different people. Quality in this study is defined as the way couples (clients) are treated by the family planning service delivery points. Assessment of the quality of service delivery in health facilities is receiving growing recognition as a strategy for monitoring and evaluation of primary health care program in developing countries (including family planning). ${ }^{[19]}$ Review of existing literatures strongly suggest that the quality of services provided are an important determinant of acceptance and continuation rates, and therefore a major contributor to increase in contraceptive prevalence rate, despite the presence of family planning services, contraceptive prevalence rate is 
low in Egypt. ${ }^{[20]}$

Client satisfaction has been widely used in the lay measurement of quality of health services. Despite its benefits, there has been growing criticism of its measurement. Satisfaction ratings reflect the personal preferences of the client, the client's expectations and the realities of the received care; the latter can be affected by different components of that care. Satisfaction ratings, being both a measure of care and a reflection of the respondent, therefore do not reflect objective reality. To overcome this problem, some organizations emphasize the measurement of client perception instead. For example, the Joint Commission on Accreditation of Healthcare Organizations has replaced the term "satisfaction" with "perception of service". Attitudes of staff are thought to influence the choices available to decision making in clinical practice. Organizational culture affects the quality of health care. "Socially complex interventions", such as the Informed Choice leaflets, should be valuated within the context in which they are used and through a prudent combination of qualitative and quantitative methods. ${ }^{[21]}$ Therefore, assessment of quality of family planning service at any level in our country is very important. Increasing quality of family planning service could help to sustain contraceptive use. This study may provide important information to family planning providers, policy makers, and program managers to improve quality of family planning service in the future.

\subsection{Aim of the study}

The aim of this study was to assess the quality of family planning services and client's satisfaction level in maternal and child health centers in Port Said city.

\subsection{Research Questions}

- What is the level of quality of family planning services?

- What is the client's satisfaction level in maternal and child health centers in Port Said City?

- Are there association between quality of family planning and client satisfaction?

\section{SubJeCtS \& METHOD}

\subsection{Research design}

A cross sectional descriptive design was used in the present study.

\subsection{Research setting}

The study was conducted in 10 maternal \& child health centers representing the five districts of Port Said. These settings include: 1-Port-Fouad first, 2-Fatma Elzahraa, 3-El manakh, 4-El kbouty, 5-Osman Ebn Afan, 6-Mostafa kamel,
7-El kuwait, 8-El gawhara, 9-Omar Ebn Elkhatab, 10-Bank elescan.

\subsection{Subjects}

It consisted of two groups of populations through five months:

First group consisted of all nurses working in, mentioned setting above, family planning centers, which were target for assessment of their practice.

Second group consisted of women using contraceptive methods and attending the family planning clinic, who were target to determine the client's satisfaction level in family planning clinics in Port Said city.

\section{Sample size}

All nurses in family planning clinic in Port Said city (20 nurses). Two nurses in each clinic.

A total of 240 contraceptive women's users were enrolled to this study who fulfilled the following criteria:

- Women at age 20-40 years.

- Women having at least two children or more, using any of contraceptive methods, were recruited in this study.

- The sample size was estimated to determine the client's satisfaction level in family planning clinics in Port Said city by using the following equation (Brown and Hollander, 1977). ${ }^{\text {[22] }}$ sample size $(n) c=P(1-P) / D^{2} \times Z^{2}$

P: Proportion of clients satisfaction about general facilities of the clinics $=65.5 \%$ (Haldar et al., 2008$){ }^{[23]}$ $\mathrm{Z}$ : A percentile of standard normal distribution determined by $95 \%$ confidence level $=1.96 ; \mathrm{D}$ : One half the width of the desired sample confidence interval = $\mathrm{P} / 10$.

The calculated sample size was 200 women. Due to the expected non-participating rate $(20 \%)$, the final sample size was 240 women.

\subsection{Tool of data collection}

Modify the tool to simple Arabic language, after literature review, for the women to suit their level of understanding. Data were collected through using three tools which were developed and used by the researchers.

Tool I: Mainly, Modified Observational checklist to measure the quality of family planning services: It was developed by USAID, 2010 ${ }^{[24]}$ to collect data about:

- Health services organization such as available seating area for client/s, enough space to see client/s, chair and table for health worker and client/s, flip chart in use, 
family planning materials on wall, family planning material available to give to client, enough space and well organized storage family planning commodities and equipment as well as group education to clients on child spacing/family planning.

- Family planning facilities such as procedure done in private room, hand-washing available in family planning room, adequate lighting available in procedure room, sharps box with cover, well ventilated room for family planning procedure, autoclave for sterilization of the equipment's, $0.5 \%$ chlorine solution or other disinfectant for cleaning equipment and Water and soap / alcohol hand rub for hand hygiene within the family planning procedure room.

- Family planning methods such as condoms, intrauterine device (IUD), injections, Implanon, progesterone only pill (POP), combined oral contraceptive (COC) and complete equipment kit available for FP procedure.

Tool II: Modified Nurse's Practice Observational checklist: It was developed from USAID, 2010 to collect information about: ${ }^{[24]}$

- Socio-demographic data such as (name, age, marital status, experiences years, and number of received training program).

- Quality of family planning counseling: it covered data about interpersonal communication skills and the steps of family planning counseling process according to GATHER technique:

- G: greeting the client.

- A: asking and assessment.

- T: telling about family planning methods, advantage and disadvantage of the methods.

- $\mathrm{H}$ : helping mother to take decision regarding family planning methods.

- E: explaining how to use the chosen method correctly.

- R: return visit for follow up.

- Measures of infection control in family planning room: it covered practice about use disposable syringes during IM/IV injection, safety precaution taken while giving injection (wearing gloves, not recapping needle), hand rub for hand hygiene with water and soap/alcohol in the family planning procedure room, disinfection or cleaning equipment, sharps box within arm's length of provider, sterilization of the equipment and proper waste disposal mechanism.

- Family planning logistics and supplies: it included data about nurses performance such as family plan- ning register, separate family planning counseling register, referral forms, family planning guidelines, family planning flipchart, family planning monthly reporting form, requisition book for family planning, card for family planning, adequate forecasting for family planning needs and if there is any plan to ensure regular supplies of family planning at the health facility.

- Family planning data management: it included information about preparing monthly report on child spacing/family planning, sending monthly report of the previous month to directorate of health affairs, copying of the report retained and stored away in an easily accessible place, the record well organized and stored away for easy access, registering total clients counseled at the facility on the day of supervision, registering total family planning client in the previous month, tallying correct of family planning methods provided in the month, registering number of family planning clients counseled for the month, and referrals document made or registers.

Tool III: Client Satisfaction Scale: It was developed from USAID, 2010 \& Hutchinson et al., 2011 to collect information about: socio demographic, family planning methods used by clients, client satisfaction about provided services, client satisfaction about providers of the services as well as future intentions of the client's to revisit the clinic. It is a five point Likert scale developed to measure the client satisfaction about family planning clinic. The scale determined very satisfied, satisfied, neither satisfied nor dissatisfied, not satisfied, not satisfied at all for attitude of clients toward family planning services provided, providers of the services and future intension of clients. ${ }^{[24,25]}$

\section{Scoring system}

- Observational checklist for quality of family planning services items, the items reported to be done were scored "2" and the items not done were scored "1". For each area, the scores of the items were summedup and the total divided by the number of the items, giving a mean score for the part. These scores were converted into a percent score, and means and standard deviations were computed. The provided services were considered satisfactory if the percent score was $60 \%$ or more, and unsatisfactory if less than $60 \%$.

- Observational checklist for nurses practice items, a correct response was scored "2" and the incorrect " 1 ". For each area of knowledge, the scores of the items were summed-up and the total divided by the number of the items, giving a mean score for the part. These scores were converted into a percent score, and means 
and standard deviations were computed. Practice was considered satisfactory if the percent score was $60 \%$ or more, and unsatisfactory if less than $60 \%$.

- Scale for client satisfaction: the responses "very satisfied", "satisfied", "neither satisfied nor dissatisfied", "not satisfied", "not satisfied at all" were respectively scored 5, 4, 3, 2, 1. The score was reversed for negative statements. The scores of the items were summed up and the total divided by the number of the items, giving a mean score. These scores were converted into a percent score, and means and standard deviations were computed. The client satisfaction was considered satisfactory if the percent score was $60 \%$ or more, and unsatisfactory if less than $60 \%$.

\subsection{Methods of data collection}

This study was covered in the following phases:

\subsubsection{Validity of tool}

The researcher designed an opinnionnaire sheet to test the content validity of the assessment questionnaire sheet for nurses and mothers by a jury including 10 experts in the field of maternity and gynecological nursing professor, obstetric and gynecological medicine professor staff. It involved two parts:

- The opinions of the experts for each item were recorded on a two point scale: relevant, not relevant and clear, not clear.

- General or overall opinion about the form, they were requested to express their opinions and comments on the tool and provide any suggestions for any additional or omissions of items. Then necessary modifications were done. This phase was carried out in a period of two months.

\subsubsection{Reliability}

Confirming the stability of the questionnaire, Cronbach's alpha was used because it gives the minimum reliability coefficient scale, beside it does not require reapplication, and it has been shown that the Cronbach's alpha coefficient equal to 0.0853 is an excellent factor in such studies.

Table 1. Reliability statistics

\begin{tabular}{ll}
\hline Tool & Cronbach's Alpha \\
\hline Quality of family planning & 0.349 \\
Socio-demographic & 0.814 \\
Nursing practices & 0.068 \\
Patient satisfactions & 0.629 \\
\hline
\end{tabular}

\subsubsection{Administrative and ethical considerations}

Approval was taken from centers directors before starting the research and data were collected after explaining the aim of the study to all participants in the study. Written letters, including the aim of the study were issued from the Dean of the Faculty of Nursing, Port Said University, to the Directorate of these centers in Port Said. Confidentiality of the study was assured clearly for every woman participating in the study. Consent from every woman before the beginning of the interview was taken. Explanation of the aim of the study was done to women to obtain their permission to participate.

\subsubsection{Pilot study}

A pilot study, which was carried out on $10 \%$ from the study subjects. The main purposes of the pilot study were to test the clarity, feasibility of the tools and whether it was understandable, and to determine the time needed to fill the tool.

\subsubsection{Field work}

Data were collected from 10 health centers representing the six districts of Port Said for four days weekly mainly Sunday, Monday, Tuesday \& Wednesday, each week. The data was collected for a period of five months from Augusts 2014 to January 2015 from above mentioned settings. The data were collected through the working days of the week according to the most working days for each health center. There were two days for each center to reach the estimated number of the sample. The tool was handed to participants to fill it and collected by researcher. The time needed by the researcher for observation quality of family planning services was 15 20 min for each clinic and 30-45 min for observation the nurse's performance to each nurse. Moreover, the time for the completion of the client Satisfaction questionnaire sheet was ranged from 20-30 minutes.

\subsubsection{Statistical design}

Data entry and analysis were done using the statistical package for social science (SPSS), version 16.0. Quality control was done at the stages of coding and data entry. Data were presented using descriptive statistics in the form of frequencies and percentages for qualitative variables, and means and standard deviations, chi-square and $p$-value for quantitative variables. Probability ( $p$-value) was considered as follows:

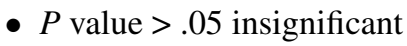

- * $P<.05$ mild significant

- ** $P<.01$ moderate significant

- *** $P<.001$ highly significant

\section{RESUlts}

Table 2 describes the quality of family planning clinic according to the physical structure and the availability of contraceptive methods in the clinics. It was found that health services are completed in all family planning clinics, $70 \%$ of family planning centers hanged family planning materials 
on wall, about more than three-quarters of them (80\%) give family planning material available to clients, as well as only $20 \%$ of them perform group education to clients on child spacing/family planning. Moreover, It is evident that the family planning practices are completed in all family planning clinics. In addition, the results reveal that family planning methods are available in all family planning clinics.

The summary of quality of the family planning services in the clinics is illustrated in Figure 1. It is evident that the majority of the clinics have satisfactory family planning services.

Table 2. Distribution of the Quality of family planning clinic according to the physical structure \& Availability of contraceptive methods in the clinics

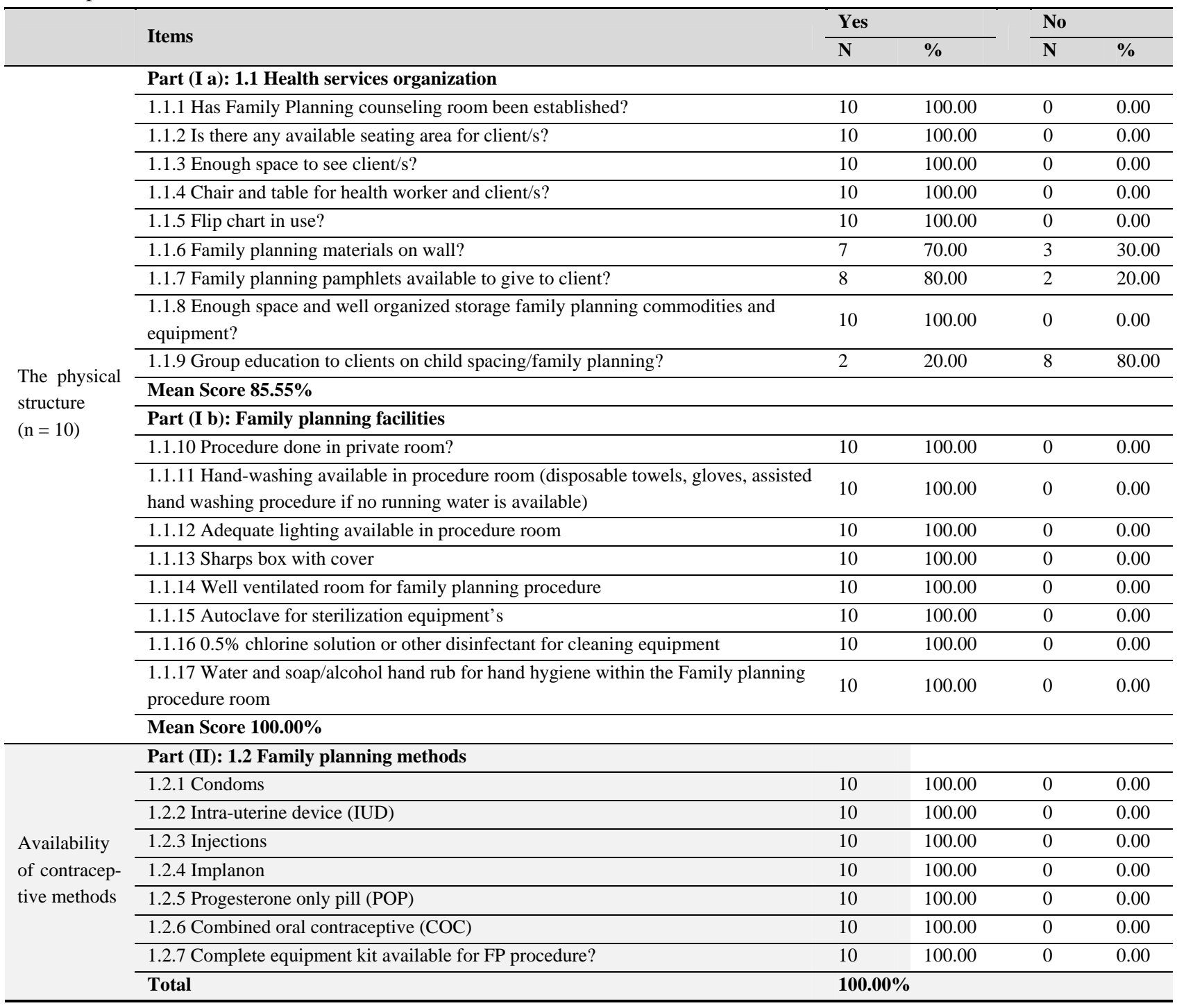

Table 3 presents the distribution of the study subjects according to their socio-demographic characteristics and special characteristics. Firstly, the nurses are according to their sociodemographic and their attended family planning training. It revealed the mean age was $36.4 \pm 8.04$ years. The majority of nurses had technical nursing school education, and half of them their years of experience less than 5 years. The same table indicates that the great majority of studied nurses had been trained in the field of family planning. About two-thirds of that nurses had (one to three) an educational and training 90 program for family planning and $75 \%$ of them took the last one less than 5 months ago before starting data collection for current study. Secondly, as evident from the table, it was found that the mean age of the clients was $31.6 \pm 7.0$ years. The great majority of them $(86.25 \%)$ were housewife and more than half $(55.41 \%)$ of them had secondary education. Regarding the family income, the same table revealed that more than half of them $(54.16 \%)$ had insufficient income. In addition, $58.33 \%$ had a high crowding index of more than 2 persons/room.

ISSN 1925-4040 E-ISSN 1925-4059 


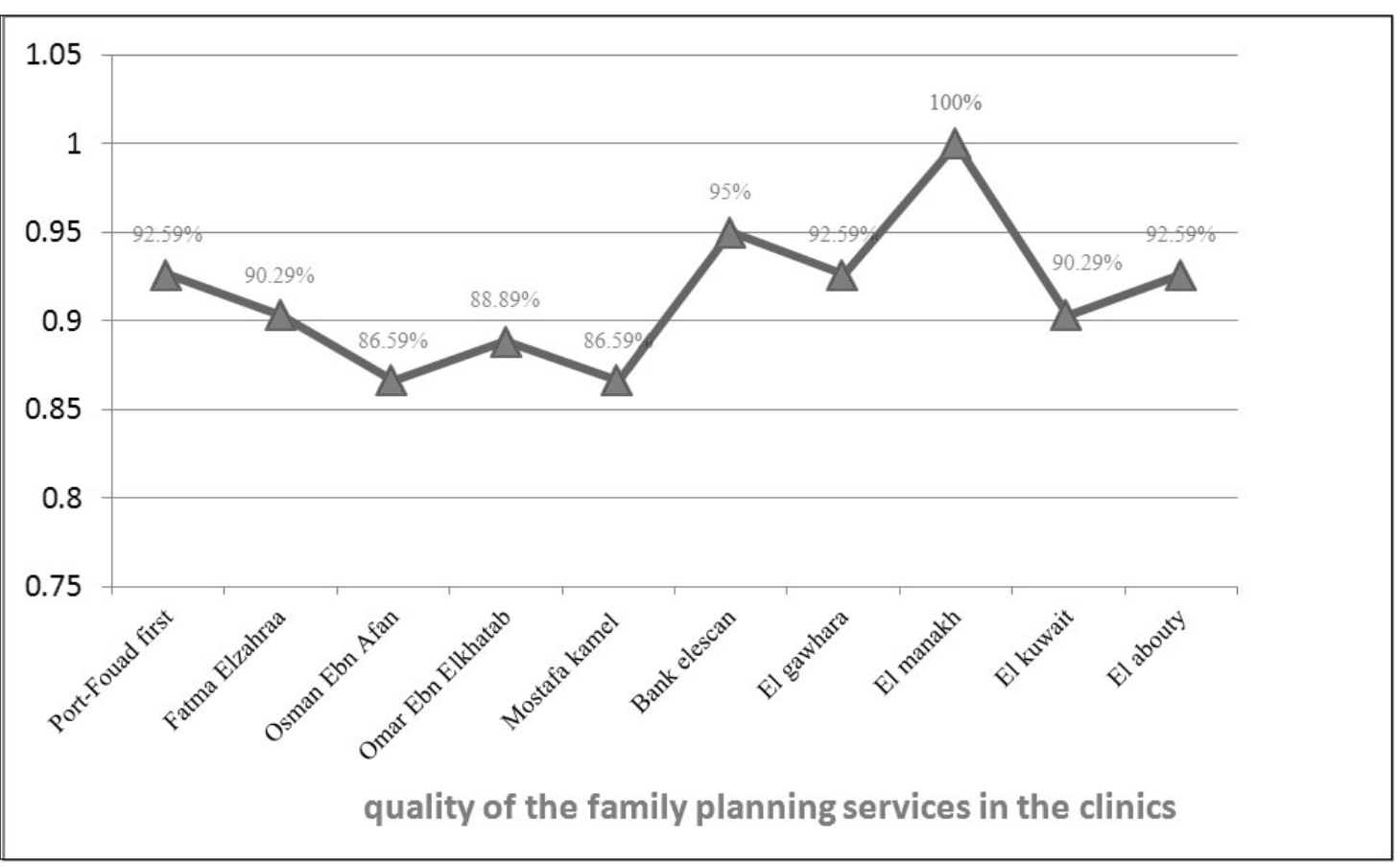

Figure 1. Summary of quality of the family planning services in the clinics

The distribution of nurse's practice according to applying the infection control measures in the clinic are displayed in Table 4. It indicates that all nurses $100 \%$ perform infection control measures in family planning room except wearing gloves $0.00 \%$, and about $5 \%$ perform water and soap/alcohol hand rub for hand hygiene in the family planning room. A statistically significant difference was found $(P=.00)$.

Table 5 illustrates the nurse's practice of family planning counseling. The majority of nurses had satisfactory performance in the following: family planning counseling techniques, except the steps of telling clients about family planning methods only $36.37 \%$ of them performed it.

Figure 2 shows the summary of the nurse's practice in providing family planning services. The results reveal that the nurses have good performance especially in family planning data management and family planning logistics and supplies. But about three-quarters (75.56\%) of nurses perform infection control measures in family planning rooms and $83.97 \%$ of nurses apply family planning counseling techniques.

Distribution of the client satisfaction is illustrated in Table 6 . Firstly, according to the provided services, the great majority of the clients were satisfied about all items related to the clinic especially in cleanliness of the examination room, availability of the methods at the clinic, cost for the family planning methods, a statistically significant difference was found. Secondly, the client satisfaction according to the providers of the services. The results revealed that the great majority of the clients were satisfied about all items related to the providers of the services especially in explanation of the provider to return the clients to the health center for followup, privacy during giving health education. A statistically significant difference was found $(P=.00)$.

Distribution of family planning services, quality nurse's practice and client satisfaction is displayed in Figure 3. As the figure shows, the mean percentage of quality of the family planning services was $96.5 \%$, while the mean percentage of level of nurse's practice $82.8 \%$, and the mean percentage of client satisfaction was $95.4 \%$.

\section{DiscuSSION}

High quality requires providing a minimum level of care to all women and a higher level of care to those who need it; obtaining the best possible medical outcome of mother; providing care which satisfies users and providers; and maintaining sound managerial and financial performance. While all these aspects are important, prioritizing among interventions to improve them will be influenced by cultural values, expectations and available resources. Quality of health care has been conceptualized in a more holistic multidimensional way. For example, the In statute of Medicine (IOM), the health arm of the US National Academy of Sciences, defines quality of health care as the degree to which health services for individuals and populations increase the likelihood of desired health out-comes and are consistent with current professional knowledge. ${ }^{[26]}$ 
Table 3. Distribution of the study subjects according to their socio-demographic characteristics

\begin{tabular}{|c|c|c|c|}
\hline & Socio-demographic characteristics & $\mathbf{N}$ & $\%$ \\
\hline \multirow{32}{*}{$\begin{array}{l}\text { Distribution of the nurses according } \\
\text { to their socio-demographic } \\
\text { characteristics and their attended } \\
\text { family planning training }(n=20) \text {. }\end{array}$} & Age (years) & & \\
\hline & $20-30$ & 7 & 35.00 \\
\hline & $31-40$ & 10 & 50.00 \\
\hline & $44+$ & 3 & 15.00 \\
\hline & Mean \pm SD & $36.4 \pm 8.04$ & \\
\hline & Level of education & & \\
\hline & Faculty of nursing & 0 & 0.00 \\
\hline & Institute of nursing & 2 & 10.00 \\
\hline & Technical nurse school & 18 & 90.00 \\
\hline & Others & 0 & 0.00 \\
\hline & Number of years of experience & & \\
\hline & Less than 5 Years & 10 & 50.00 \\
\hline & 5-15 Years & 8 & 40.00 \\
\hline & 16-30 Years & 1 & 5.00 \\
\hline & More than 30 Years & 1 & 5.00 \\
\hline & Mean \pm SD & $1.64 \pm 0.79$ & \\
\hline & Training in the field of family planning & & \\
\hline & Yes & 19 & 95.00 \\
\hline & No & 1 & 5.00 \\
\hline & Mean \pm SD & $1.95 \pm 0.20$ & \\
\hline & Number of received training program & & \\
\hline & No Training & 1 & 5.00 \\
\hline & $1-3$ & 14 & 70.00 \\
\hline & $4-7$ & 3 & 15.00 \\
\hline & $8-10$ & 2 & 10.00 \\
\hline & Mean \pm SD & $2.41 \pm 0.80$ & \\
\hline & Date of last training & & \\
\hline & No Training & 1 & 5.00 \\
\hline & Less than 5 Months & 15 & 75.00 \\
\hline & From 5 Months to One Year & 3 & 15.00 \\
\hline & More than one Year & 1 & 5.00 \\
\hline & Mean \pm SD & $2.23 \pm 0.53$ & \\
\hline \multirow{21}{*}{$\begin{array}{l}\text { Frequency distribution of } \\
\text { socio-demographic characteristics } \\
\text { of the client sample }(n=240) \text {. }\end{array}$} & Age (years) & & \\
\hline & -31 & 123 & 51.25 \\
\hline & $31-41$ & 90 & 37.5 \\
\hline & $41+$ & 27 & 11.25 \\
\hline & Mean \pm SD & $31.6 \pm 7.0$ & \\
\hline & Job & & \\
\hline & Employed & 33 & 13.75 \\
\hline & Housewife & 207 & 86.25 \\
\hline & Education level & & \\
\hline & Un educated & 55 & 22.91 \\
\hline & Reading \& write & 23 & 9.58 \\
\hline & Secondary education & 133 & 55.41 \\
\hline & Higher education & 29 & 12.08 \\
\hline & Family income & & \\
\hline & Insufficient & 130 & 54.16 \\
\hline & Sufficient & 110 & 45.83 \\
\hline & Mean \pm SD & $2.33 \pm 0.69$ & \\
\hline & Crowding index (persons/room) & & \\
\hline & 2 & 100 & 41.66 \\
\hline & $2+$ & 140 & 58.33 \\
\hline & Mean \pm SD & $2.14 \pm 0.62$ & \\
\hline
\end{tabular}


Table 4. Distribution of the Nursing practices regarding their application of infection control measures in the clinic

\begin{tabular}{|c|c|c|c|c|c|c|}
\hline \multirow{2}{*}{ Items } & \multicolumn{2}{|l|}{ Yes } & \multicolumn{2}{|l|}{ No } & \multirow{2}{*}{ Chi-Square } & \multirow{2}{*}{$P$-value } \\
\hline & $\mathbf{N}$ & $\%$ & $\mathbf{N}$ & $\%$ & & \\
\hline \multicolumn{7}{|l|}{ 2. Infection Prevention and Control in Family Planning Procedure Room } \\
\hline 2.1 Use disposable syringes during IM/IV injection & 20 & 100.00 & 0 & 0.00 & -- & -- \\
\hline \multicolumn{7}{|l|}{ 2.2 Safety precaution taken while giving injection: } \\
\hline - wearing gloves & 0 & 0.00 & 20 & 100.00 & -- & -- \\
\hline - $\quad$ not recapping needles & 20 & 100.00 & 0 & 0.00 & -- & -- \\
\hline $\begin{array}{l}2.3 \text { Hand rub for hand hygiene with water and soap/alcohol in the Family } \\
\text { planning procedure room }\end{array}$ & 1 & 5.00 & 19 & 95.00 & 18.18 & $.00 *$ \\
\hline 2.4 Disinfect or clean equipment & 20 & 100.00 & 0 & 0.00 & -- & -- \\
\hline 2.5 Sharps box within arm's length of provider & 20 & 100.00 & 0 & 0.00 & -- & -- \\
\hline 2.6 Sterilize family planning equipment & 20 & 100.00 & 0 & 0.00 & -- & -- \\
\hline 2.7 Proper waste disposal mechanism (incinerator with fence, covered pit etc.) & 20 & 100.00 & 0 & 0.00 & -- & -- \\
\hline \multicolumn{7}{|c|}{ Mean score $75.56 \%$} \\
\hline
\end{tabular}

$(*)$ Statistically significant at $P<.05$

Table 5. Distribution of nurse's application of family planning counseling

\begin{tabular}{lll}
\hline Quality of family planning counseling & $\mathbf{N}$ & $\mathbf{\%}$ \\
\hline Introducing themselves to clients & 0 & 0.00 \\
Greeting & 18 & 88.64 \\
Asking & 20 & 100.00 \\
Telling & 6 & 36.37 \\
Helping & 19 & 97.73 \\
Explaining & 16 & 81.06 \\
Referring/follow up & 20 & 100.00 \\
$\quad$ Mean Score & & $\mathbf{8 3 . 9 7 \%}$ \\
\hline
\end{tabular}

Providers should have the necessary technical skills to of- and continuation. fer the methods safely, be trained in technically accurate \& culturally appropriate counseling techniques, and be able to use this knowledge effectively. Services should be convenient, accessible and acceptable to clients. In addition, it is essential to provide follow-up care to ensure continuity of services and an adequate logistics system to ensure continuity of supplies. ${ }^{[11]}$ In this section, we discuss findings in two areas related to these core elements: facility readiness to provide quality services, and health care provider facilitation of informed method choice. We also review the literature on client satisfaction and its relationship to contraceptive use

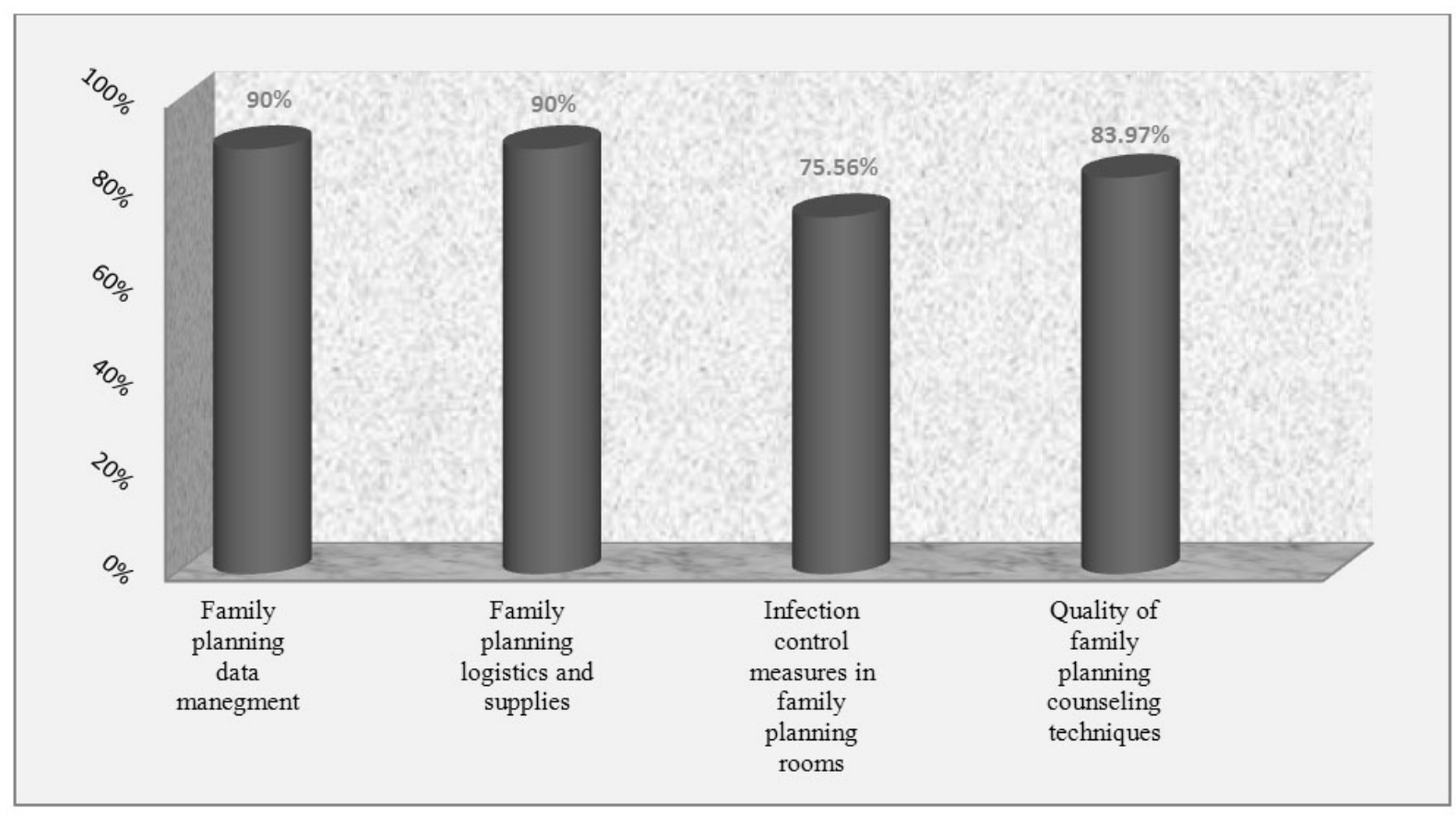

Figure 2. Summary of the nurse's practice in providing family planning services 
Table 6. Distribution of the client's satisfaction regarding the quality of the provided and the providers of the services

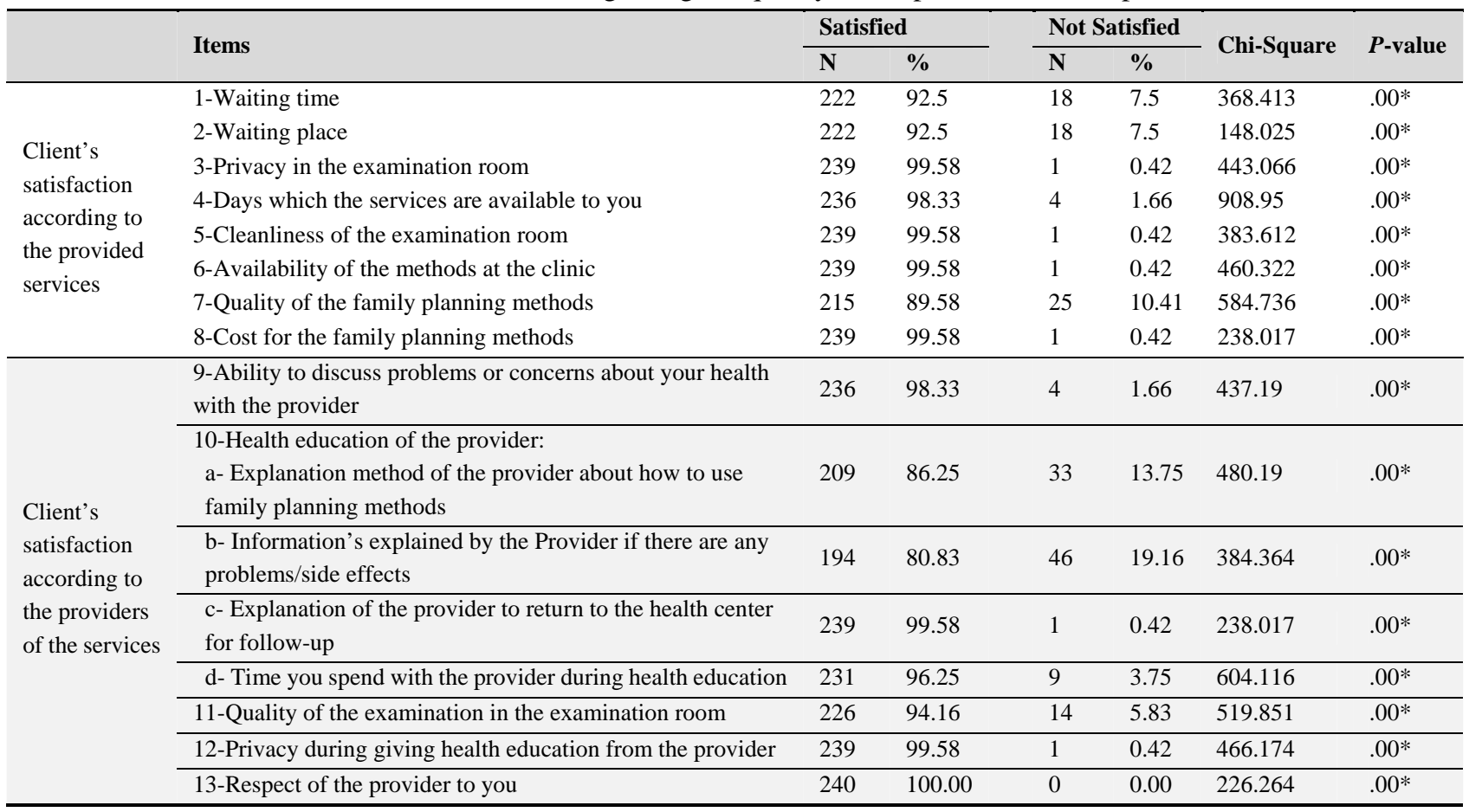

(*) Statistically significant at $P<.05$

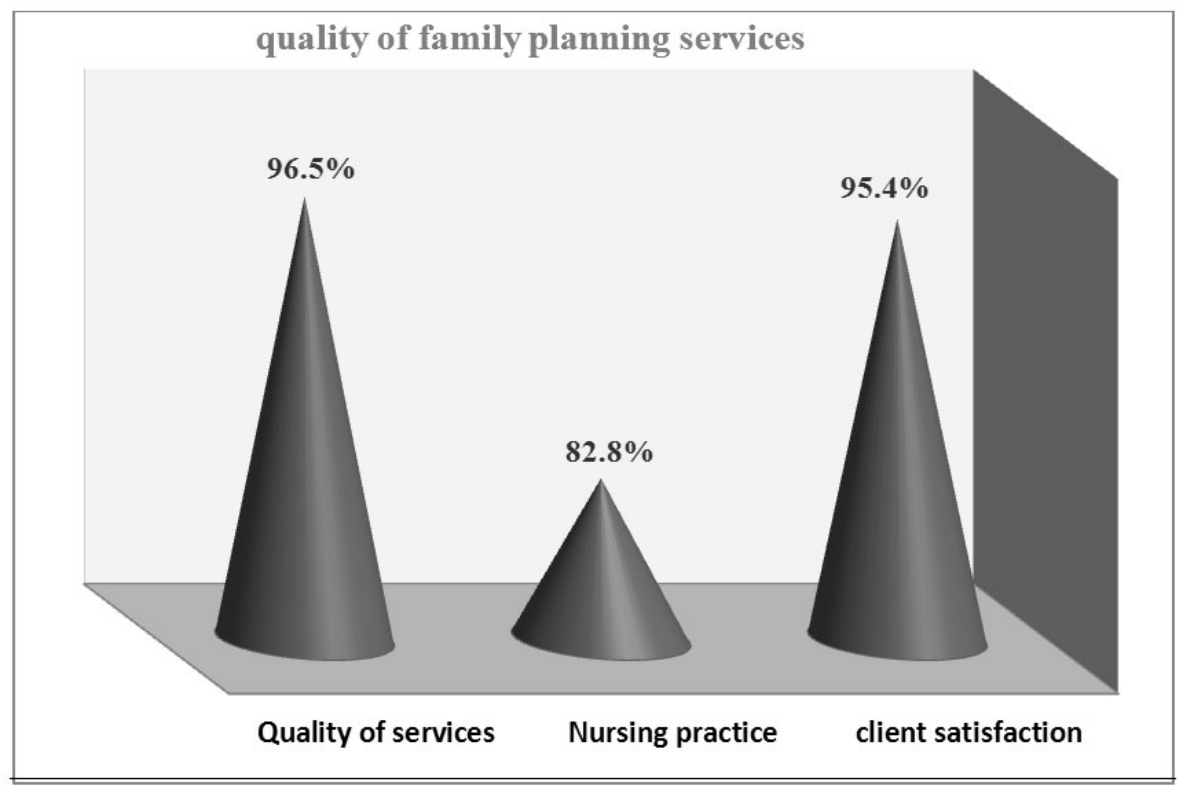

Figure 3. Association between the quality of family planning services, nurses practice and client satisfaction

Potter et al., (2006) stated that educating the clients is a role for nurses in all health care settings in primary health care settings, the nurse is often the main source of information about health promotion and illness prevention. ${ }^{[27]}$ Allender \& Spradley (2006) added that a client remains interested when the nurse is enthusiastic during conducting a health education session by using nonverbal skills, a good nurse carefully plans the order in which to present information. ${ }^{[28]}$ If nurse lacks professional knowledge, she should be given appropriate instruction and training. Hence, it is implied that the health care institution must develop comprehensive continuing educational programs. ${ }^{[29,30]}$ It was noticed, from 
the findings of the present study, that there are only $20 \%$ of family planning centers, which perform group education to clients on child spacing/family planning. This result reflects that, either nurses did not have adequate level of professional knowledge or they were overloaded so, they didn't have enough time to do. In addition, this may be attributed to client's refusal to attend that program as they consider it time wasting result of long waiting in the center. Ndlebe S. (2011) emphasized that the participants reported lack of reproductive health education at the clinics. ${ }^{[31]}$

About $90 \%$ of nurses perform family planning logistics and supplies in all family planning centers. This finding is in line with USAID, (2009 \& Tseganeh (2005) which found that all family planning service delivery points had monthly family planning logistics and supplies due to supervisory visits on the family planning clinics. ${ }^{[32,33]}$ In the same line, the present study revealed that $90 \%$ of all nurses perform family planning data management in family planning clinics except referral forms to other hospitals or centers which were not documented $0.00 \%$. This is supported by Department of Health and Human Services (2009) who stated that the percent of respondents obtained a primary care referral $0.00 \%$ in all family planning clinics. ${ }^{[34]}$ Also, Illinois Health Connect (2011) reported that, the nurses think that there are no urgent cases in family planning clinics and there is no need for referrals. This includes talking to someone on how to plan for a healthy birth and about birth control. The client can get this care if he has problem from the family planning provider or any doctor or clinic that takes the medical card. ${ }^{[35]}$

Regarding family planning facilities, it is evident that the family planning facilities are completed in all family planning clinics. This result was not amazing since family planning is a priority program of the Ministry of Health \& Population (MOHP) and a component of the reproductive health package \& essential health care services of the Egyptian Health Sector Program. In addition it reflects the collaboration of governmental and national organizations with ministry of health and population. This result is in agreement with Engender Health (2004) which found that all facilities needed in family planning clinics were completed. ${ }^{[36]}$ In the same line, the present study revealed that there are $100 \%$ of family planning methods are available in all family planning clinics. A similar finding was reported by other researcher who found that the majority of the health facilities observed had supplies of essential family planning devices such as condoms, pills, injections, IUD and Norplant, all are stored in the facility at the time of the assessment. ${ }^{[37]}$

According to the current study findings, it was revealed that the great majority of nurses have been trained in family plan- ning clinics, and only 5\% were not trained. These findings were expected as the ministry of health and population doing its best for improving quality of family planning services by continuous in-services educational training programs. This finding is in agreement with WHO, (2007) which reported that continuing or refresher training is as important as initial training. ${ }^{[38]}$ A number of studies have found that if regular refresher training is not available, acquired skills and knowledge are quickly lost; and that, good continuing training may be more important and effective on the performance of the nurses in family planning clinics. Similarly, Tuoane, (2004) mentioned that twenty-nine percent of providers had received training in the field of family planning, but an additional $6 \%$ had received no training in the field of family planning at all. ${ }^{[39]}$ There are about $15 \%$ who received $4-7$ training program and more than two-thirds of them had 1-3 training program, and $75 \%$ of them took training less than 5 months ago, which reflect that there are continuing training alternately between all nurses in family planning clinics.

The role of nursing is expanded and strengthened as experts with profession fill the void in women's health care. Women can now receive total assessment, planning treatment, education, counseling and support from nurse. ${ }^{[4]}$ Also over the last 10 years, the role of nurses in family planning clinics has increased dramatically. ${ }^{[39]}$ Additional training and professional developments within nursing generally, means that nurses now undertake many of the extended clinical roles previously performed by doctors. This increasing autonomy means that many family planning clinics now are run by "nurse only" sessions, where no doctor is present.

Concerning family planning counseling, it was noticed that the great majority of nurses applied the element of counseling satisfactory but they need more training. Reasons for that as nurses were not interested, had time shortage and some of them did not have adequate level of knowledge. ${ }^{[33]}$ This was not amazing since majority of nurses (90\%) in the present study were moderately educated level (technical nurse school). In addition, staff nursing shortage ( 2 nurses only for clinic) add extra effort on them, that is why they were not interested. Despite the majority of nurses (88.64\%) greet the women's satisfactory none of the nurses $(0.00 \%)$ introduce herself to clients. These finding is in agreement with those of the study conducted by National Health Training Center (2006). ${ }^{[37]}$ Moreover, $36.37 \%$ of nurses provided information on contraceptive methods and birth spacing which agreed with Nanbakhsh et al. (2008) who denote that, 36\% of nurses provided information on contraceptive methods and birth spacing. ${ }^{[40]}$

About $97.73 \%$ of nurses help the clients to arrive to the best 
method of their choices. This finding is in line with National Health Training Center (2006), which almost had the same results. ${ }^{[37]}$ Also Tseganeh (2005) denoted that when clients get different methods in the health service delivery points, they can get the chance to prefer their choice. When clients get the method they want, they use them longer and more effectively. ${ }^{[33]}$ In addition, It was noticed that, there was about more than three-quarters of nurses explained the information about the chosen method. This result is congruent with the results of Tseganeh (2005) who reported that $82.9 \%$ of nurses explained the chosen method in Kenya. ${ }^{[33]}$ This is not sufficient and attention has to be given since each client has the right to get information. Clients' lack of information regarding to the above issues is likely to result in a negative attitude towards methods whenever they experience the above problems. This might increase the probability of discontinuation of contraceptive methods. Similar studies held by National Health Training Center (2006), who found that about $84.6 \%$ of nurses explain the chosen method to the client's. ${ }^{[34]}$ Furthermore, all nurses provide information on referral and next appointment. This finding almost is in agreement with the study conducted by National Health Training Center (2006), which reported that about $95.8 \%$ of nurses provide information on referral and next appointment. ${ }^{[37]}$ Similarly, Engender Health (2004) stated that $100 \%$ clients are told when to return for routine follow-up, including sources of care, if needed. ${ }^{[35]}$

Since the 1980s, interest in the measurement of patients' satisfaction with their healthcare experiences has increased, following reports that high patient satisfaction is associated with better health outcomes. ${ }^{[41-43]}$ This has not been universally accepted, however, Chang J. et al. \& Fisher E. et al. and the debate over using patient satisfaction ratings as a quality-of-care marker continues. ${ }^{[44,45]}$

The present study was also concerned about assessing client satisfaction concerning nurse's practice in family planning. It was noticed that, there are none of the nurses wear gloves in the family planning room during the procedure which means that the nurses need more training in this field. This finding was opposing the results of the study done by Cohen, (2004) who found that $56 \%$ did not wear gloves all of the time. On the other hand, the proportion of those who did not use gloves routinely was lower among those who reported a break in precautions occurred because the equipment was not effective, $22 \%$ did not wear gloves all of the time and among those who forgot, $30 \%$ did not wear gloves all of the time. ${ }^{[46]}$ However, about three-quarters of nurses performed infection prevention and maintaining sterile technique in family planning procedure rooms. This result may be due to supervisory visits, from infection control unit in the ministry of health, on the family planning clinics. This finding is in agreement almost with these study conducted by Taneja (2009) who stated that about $75.5 \%$ of nurses pertaining the practice of infection control measures, and emphasized that the infection control products help to reduce infections by between $52 \%$ \& $91 \%$. ${ }^{[47]}$

Contraceptive client satisfaction is crucial to delivering clientcentered care, assess the quality of care and client's satisfaction highlights successes and identify the factors that affect and opportunities for improvement. The nurses can help the couple to achieve their objectives by teaching them about contraceptive options. ${ }^{[48]}$ The role of the nurse in family planning is acknowledged by the World Health Organization. She must be able to prove reliable and up to date information. Her counseling skills are of paramount importance and she must be careful never to make moral judgments. Knowledge of colloquial names for contraceptive methods and part of the body is desirable. ${ }^{[4]}$

Patient satisfaction is reportedly a useful measure to provide a direct indicator of quality in healthcare, hence needs to be measured frequently. Therefore, this study was to measure quality of family planning services in family planning clinics. Through determining the quality of family planning services, assessing the client's satisfaction level in family planning clinics and identifying the nurse's practices in family planning clinics. It was obvious from the findings of this study that more than two quarters of family planning centers hang family planning materials on the wall. This reflects the availability of these materials. This is supported by National Health Training Center (2006) which mentioned that the majority of the health facilities have some form of materials displayed in the health facility and the counseling room. In addition, the displayed materials were positioned in a manner such that they could be easily visible and read by the clients visiting the health facilities. In addition, it emphasized that the counseling room has materials available for distribution in about $82.4 \%$. This finding in line with the present study which mentioned that about more than three-quarters $(80 \%)$ of family planning centers give family planning material available to their clients. ${ }^{[37]}$

The findings of the present study showed that, the great majority $(99.59 \%)$ of the clients were satisfied about all items related to the clinic especially in cleanliness of the examination room, availability of the methods at the clinic privacy during giving health education from the provider and cost for the family planning methods. The cost for the family planning methods is a vital point for women as the great majority of them $(86.25 \%)$ were housewife and more than half of them $(54.16 \%)$ had insufficient income. These result 
are supported by Hutchinson \& Agha (2011) who mentioned that clients reported that they were satisfied and had no problems with all of the following: waiting time $93.1 \%$, ability to discuss concerns with provider $97.2 \%$, amount of explanation given $92.0 \%$, quality of examination and treatment provided $96.2 \%$, visual privacy during examination $97.1 \%$, auditory privacy during examination $96.7 \%$, availability of the methods at facility $97.6 \%$, hours of service provision $96.0 \%$, cleanliness of facility $99.5 \%$ and how the staff deals with the client $100 \%$. ${ }^{[49]}$

In the same line and in agreement with the present study finding, author has reported that around $95.8 \%$ of all the clients mentioned that they would return to the health facility for future services. In addition, around $97 \%$ of the clients mentioned that they would suggest others to visit the health facility. ${ }^{[37]}$ This result reflects their high level of satisfaction related to the high quality of care in family planning services which provided to them. Agwanda, (2009) mentioned that client opinion especially satisfaction with services, is a subjective way of measuring quality of family planning services. Satisfied clients are more likely to re-visit the services, pass on positive messages by word of mouth to others, and continue to use a particular family planning method. On the other hand, dissatisfied clients are more likely to share their negative experiences with others and are less likely to return or continue the use of family planning services. ${ }^{[50]}$ In addition, Hutchinson \& Agha (2011) emphasized that the previous studies have found that the quality of client-provider interactions contributes significantly to client satisfaction and contraceptive continuation. In this study certainly the evidence exists to show that higher levels of client satisfaction with process measures of quality increases the likelihood of contraceptive use and continuation. But structural measures of quality, such as frequent shortages of methods or inappropriate guidance, are also likely to inhibit long-term contraceptive continuation. ${ }^{[49]}$

Thus, client's satisfaction is an important issue both for evaluation and improvement of healthcare services. ${ }^{[51]}$ User evaluations educate medical staff about their achievements as well as their failure, assisting them to be more responsive to their patients' needs. Patient's assessment, therefore, suggests guidelines for improving the attitudes of doctors and other paramedic staff in better serving the patients thereby improving the health services. ${ }^{[52]}$ It was revealed from the finding of this study that, there is high quality in family planning services which represented $96.5 \%$, while there was adequate level of nurses practice $82.8 \%$ which means that the nurses need more training in family planning, as well as there was a high level of client satisfaction $95.4 \%$. This is supported by National Health Training Center (2006) which

Published by Sciedu Press stated that the quality in family planning services constituted $95.4 \%$, while the level of nurse's practice $83.3 \%$, as well as the level of client satisfaction $95.8 \% .^{[37]}$

\section{CONCLUSiON}

Based on study findings, it can be concluded that: It was proved that the most of maternal \& child health care centers has good quality level in health services organization, facilities available in the clinics, family planning methods and equipment's except performing group education to clients on child spacing/family planning and hanging materials of family planning on the wall. Moreover, most of nurses are train and have adequate level in counseling and applying infection control measures but need more training. In addition, the great majority of nurse's have satisfactory practice on family planning logistics, supplies and family planning data management. Significantly, the majorities of the clients was satisfied about the provided services, provider of services, and have intention to revisit the clinic in the future. Also, they recommend visiting the clinic to other women. In addition, it was proved from the study that the factors affecting client satisfaction are highly affected by the providers of the services in the family planning clinics, and then the services provided to the clients in the clinics.

\section{RECOMMENDATION}

Based on the present study findings, the following recommendations the follows:

- There is a need for continuous retraining of family planning service providers so that they are up-to-date with emerging trends in contraceptive advancement and provision of effective counseling.

- Regular group education should be designed based on current scientific knowledge to impact correct and accurate knowledge about family planning. This is to avoid misinformation, wrong teaching and misbelieves that constitute the present structured teaching on different contraceptive methods.

- Quality should be considered as an integral part of family planning services.

- Set up referral places for clients and ensure that they know exactly where and when to go and give them clear directions.

- Establish a system for supervision, recognition of good performance and rewarding of nurses in the clinic to encourage them and to increase job satisfaction.

\section{CONFlicts OF InTEREST Disclosure}

The authors declare that there is no conflict of interest. 


\section{REFERENCES}

[1] Dat V, Colin W, Andy H, et al. Measuring client-perceived quality of maternity services in rural Vietnam. International Journal for Quality in Health Care. 2014; 16(6): 447-452.

[2] Martha C, Maureen C, Suzanne D, et al. Transforming Maternity Care - 2020 Vision for a High Quality, High Value Maternity Care System, Blueprint for Action and Proceedings from the Childbirth Connection 90th Anniversary Symposium, Maternity Care System, Women's Health Issues. 2009; 20 (1): S7-S17.

[3] Kamell R, Wassif S. Population Problem In Egypt As One of The Priority Health Problems In Tropical Areas. Zagazig Journal of Occupation Health and Safety. 2008; 1(2): 87.

[4] Basavanthappa BT. Community Health Nursing. 2nd edition. Jaypee Publishers. NewDelhi: 2008. 561-562. http://dx.doi.org/10. 5005/jp/books/10159

[5] Khattab HAS, Zaky HHM, Galal D. Assessing the Quality of Reproductive Health Services in Egypt via Exit Interviews, Springer Science + Business Media. 2007; 11: 301-306.

[6] Scott A, Glasier A. Evidence based contraceptive choices, Best Practice Research Clinical Obstetrics \& Gynaecology. 2006; 20(5): 665 680. PMid:16707277 http://dx.doi.org/10.1016/j.bpobgyn .2006 .03 .002

[7] Abdel-Tawaba N, Roterb D. The relevance of client-centered communication to family planning settings in developing countries: Lessons from the Egyptian experience. Elsevier Science Ltd; 2002; 54: $1357-$ 1368.

[8] Veres S, Miller L, Burington B. A comparison between the vaginal ring and oral contraceptives Obstetrics and Gynecology. 2004; 104(3): 555-563. PMid:15339769 http://dx.doi.org/10.1097 /01.AOG.0000136082.59644.13

[9] Blumenfelds SN. Quality assurance in transition. Papua New Guinea Medical Journal. 1993; 36(2): 81-89.

[10] Blumenthal D. Quality of care-what is it? New England Journal of Medicine. 1996; 335(12): 891-893.

[11] Bruce J. Fundamental elements of the quality of care: A simple framework studies in family planning. 1990; 21(2): 61-91.

[12] DE Gynd TW. Managing the quality of health care in developing countries. Washington, D.C World Bank, World Bank technical papers. $1995.258,89$.

[13] Donabedian A. The quality of care: How can it be assessed? Journal of American medical association. 1998; 260(12): 1743-1748. http://dx.doi.org/10.1001/jama.1988.03410120089033

[14] Brook RH, McGlynn EA, Shekelle PG. Defining and measuring quality of care: a perspective from US researchers. Int J QualHealth Care. 2000; 12: 281-295. http://dx.doi.org/10.1093/intqhc/12 .4 .281

[15] UN report of international conference on population and development (ICPD). New York, 1995.

[16] Diat M. Informed choices in international F/P service delivery. Bellago, Italy. 1999. PMid:9852315

[17] Andaleeb SS. Service quality perceptions and patient satisfaction: a study of hospitals in a developing country. Soc Sci Med. 2001 52: 1359-1370. http://dx.doi.org/10.1016/S0277-9536(00 ) 00235-5

[18] Edwards C, Staniszewska S, Crichton N. Investigation of the ways in which patients' reports of their health care are constructed. Sociol Health Illn. 2004; 26: 159. PMid:15027983 http://dx.doi.org /10.1111/j.1467-9566.2004.00385.x

[19] WHO. Program for the control of diarrheal disease. Health facility case management survey guide lines Geneva, WHO. 1990.
[20] Jain AK. Fertility reduction and the quality of family Planning service. Studies in Family Planning. 2000; 20(1): 1-16. http: //dx.doi.org/10.2307/1966656

[21] Helen S, Mavis K, Gwenan T. Qualitative study of evidence based leaflets in maternity care. BMJ. 2002; 324: 639. http://dx.doi.o $\mathrm{rg} / 10.1136 / \mathrm{bmj} .324 .7338 .639$

[22] Brown M, Hollander JW. Statistics: A Biomedical Introduction. Mathematics, Wiley series in probability and mathematical statistics, John Wiley \& sons, Inc, New York: 1977. 456. http: //dx.doi.o $\mathrm{rg} / 10.1002 / 9780470316474$

[23] Haldar A, Sarkar AP, Bisoi S, et al. Assessment of Client's Perception in Terms of Satisfaction and Family Planning service. Indian J Community Med. 2008 Apr; 33(2): 121-123. PMid:19967039 http://dx.doi.org/10.4103/0970-0218.40883

[24] USAID, United States Agency for International Development. Supportive Supervision Checklist on Htsp and Family Planning for Health Facilities. 2010.

[25] Hutchinson PL, Do M, Agha S. Measuring client satisfaction and the quality of family planning services: A comparative analysis of public and private health facilities in Tanzania, Kenya and Ghana, BMC Health Services Research. 2011; 11(203): 6. http: //dx.doi.org/10.1186/1472-6963-11-203

[26] Rudiger P, Oona M, Veronique G. What is quality in maternity care? An international perspective, Acta Obstetricia et Gynecologica Scandinavica. 2002; 81: 277-283. http://dx.doi.org/10.1034/j.1 600-0412.2002.810401.x

[27] Potter PA, Perry AG, Ross-Kerr JC, et al. Canadian Fundamentals of Nursing (3rd Ed.). Elsevier, Canada: 2006; 600-610.

[28] Allender AJ, Spradley WB. Community Health Nursing, 5th ed., New York, Lippincott: 2006. 317-319.

[29] Shattell M. Nurse-patient interaction: a review of the literature. Journal of Clinical Nursing. 2004; 13: 714-722. PMid:15317511 http://dx.doi.org/10.1111/j.1365-2702.2004.00965.x

[30] Kim Y, Heerey M, Kols A. Factors that enable nurse-patient communication in a family planning context: A positive deviance study. International Journal of Nursing Studies. 2008; 45(10): 14111421. PMid:18289545 http://dx.doi.org/10.1016/j.ijnur stu. 2008.01.002

[31] Ndlebe S. An Assessment Of The Quality Of Family Planning Services Rendered To Adolescents By Health Workers At Mdantsane Clinis, Mdantsane, Eastern Cape Province, S.A., Master Thesis, University of Fort Hare, South Africa: 2011. 57.

[32] USAID, United States Agency for International Development. Contraceptive Logistics Management System Assessment Report, Nigeria. 2009. Available from: http://www.nigeria.unfpa.org/pd $\mathrm{f} / \mathrm{ng}$ _contlogimanaasse.pdf

[33] Tseganeh W. Assessment of Quality of Family Planning Services, Bahar-Dar Special Zone, Amhara Regional State, Master Thesis of Public Health, department of community health, Addis Ababa University. 2005. 10-12\&39-57.

[34] Department of Health and Human Services. Medicaid Be Smart Family Planning Waiver Waiver Year Four Primary Care Referrals Report on Female and Male Participant Surveys. 2009.

[35] Illinois Health Connect. Primary Care Provider Hand Book. 2011. Available from: http://www.illinoishealthconnect.com

[36] Engender Health. Improving Access and Quality of Clinical Family Planning Services in the Public and Private Sectors in Ghana. End of Project Report. Accra, Ghana: Engender Health. 2004: 29-37.

[37] National Health Training Center. Assessment of Providers' Performance: COFP/Counseling Training, Ministry of Health and Population, Government of Nepal. 2006. 14\&51-78. 
[38] WHO, World Health Organization. Community health workers: What do we know about them? The state of the evidence on programmes, activities, costs and imp. 2007.

[39] Tuoane M, Madise NJ, Diamond I. Provision of Family Planning Services in Lesotho, Guttmacher Institute. 2004; 30(2): 9. http: //dx.doi.org/10.1363/3007704

[40] Nanbakhsh H, Salarilak S, Islamloo F, et al. Assessment of women's satisfaction with reproductive health services in Urmia University of Medical Sciences, Eastern Mediterranean Health Journal. 2008; 14(2): 608-611.

[41] Institute of Medicine. Crossing the Quality Chasm: A New Health System for the 21st Century. Washington, DC: National Academies Press; 2001.

[42] Bertakis KD, Azari R. Patient-centered care is associated with decreased health care utilization. J Am Board Fam Med. 2011; 24: 229-239. PMid:21551394 http://dx.doi.org/10.3122/jabfm .2011 .03 .100170

[43] Groene O. Patient centredness and quality improvement efforts in hospitals: rationale, measurement, implementation. Int J Qual Health Care. 2011; 23: 531-537. PMid:21862449 http://dx.doi.org/1 $0.1093 /$ intqhc/mzr058

[44] Fisher ES, Wennberg DE, Stukel TA, et al. The implications of regional variations in Medicare spending. Part 2: health outcomes and satisfaction with care. Ann Intern Med. 2003; 138: 288-298. http: // dx.doi.org/10.7326/0003-4819-138-4-200302180-00007

[45] Chang JT, Hays RD, Shekelle PG, et al. Patients' global ratings of their health care are not associated with the technical quality of their care. Ann Intern Med. 2006; 144: 665-672. http://dx.doi.org /10.7326/0003-4819-144-9-200605020-00010

[46] Cohen HA, Kitai E, Levy I, et al. Hand-washing Patterns in Two Dermatology Clinics. Dermatology. 2004; 205(4): 358-361. http: //dx.doi.org/10.1159/000066421

[47] Taneja J. Evaluation of knowledge and practice amongst nursing staff toward infection control measures in a tertiary care hospital in India, The Canadian Journal of Infection Control. 2009; 24(2): 103-105.

[48] Pillitteri A. Maternal \& Child Health Nursing Care of the Child Bearing \& Child Rearing Family. 5thed, California: Lippincott Williams \& Wilkins co. 2007. 101-123.

[49] Hutchinson PL, Do M, Agha S. Measuring client satisfaction and the quality of family planning services: A comparative analysis of public and private health facilities in Tanzania, Kenya and Ghana, BMC Health Services Research. 2011; 11(203): 6. http: //dx.doi.org/10.1186/1472-6963-11-203

[50] Agwanda A, Khasakhala A, Kimani M. Assessment of Family Planning Services in Kenya: Evidence from the 2004 Kenya Service Provision Assessment Survey. Kenya Working Papers No. 4. Calverton, Maryland, USA: Macro International Inc: 2009. 1-12.

[51] Al-Eisa IS, Al-Mutar MS, Radwan MM, et al. Patients' satisfaction with primary health care services at capital health region, Kuwait Middle East J Fam Med. 2005; 3: 277-300.

[52] Al-Qatari GM, Haran D. Determinants of satisfaction with primary health care settings and services among patients visiting primary health care centres in Qateef, Eastern Saudi Arabia. Middle East J Fam Med. 2008; 6: 3-7. 